\title{
Educação profissional técnica e tecnológica no IFPR: a educação especial em questão
}

\author{
Technical and technological professional education at \\ the IFPR: the special education in question
} Educación profesional técnica y tecnológica en la IFPR:
la educación especial en cuestión

LUCILIA VERNASCHI DE OLIVEIRA (iDa

SOLANGE FRANCI RAIMUNDO YAEGASHIDb

NATHÁLIA FAFARÃO RUIZiDc

\section{Resumo}

A educação especial é uma modalidade de ensino para estudantes com deficiência, Transtorno do Espectro Autista (TEA) e com altas habilidades e superdotação, matriculados nas diferentes etapas e níveis de ensino. Traçamos o objetivo de analisar ações institucionais de educação especial no Instituto Federal de Educação (IFPR) nos cursos profissionais técnicos e tecnológicos. Trata-se de uma pesquisa qualitativa, de natureza documental e bibliográfica. Inicialmente, apresentamos de forma geral a educação especial como modalidade de ensino que busca se efetivar por meio de dispositivos legais e de pressupostos teórico-metodológicos, a partir de temáticas específicas que tratam de recursos e serviços de acessibilidade no atendimento às especificidades do seu público. Na sequência, elencamos alguns dos principais documentos do IFPR que dispõem sobre a inclusão escolar, com ênfase nos direitos das pessoas que são público da educação especial. Para se compreender o que dizem as pesquisas stricto sensu acerca de investigações

\footnotetext{
a Instituto Federal do Paraná (IFPR), Umuarama, PR, Brasil. Doutora em Educação, e-mail: luvernaschi@gmail.com

b Universidade Estadual de Maringá (UEM), Maringá, PR, Brasil. Doutora em Educação, email: solangefry@gmail.com

c Universidade Estadual de Maringá (UEM), Maringá, PR, Brasil. Doutoranda em Educação, e-mail: nathalia-mga@hotmail.com
} 
realizadas em diferentes campi do IFPR, realizamos busca no catálogo de teses e dissertações da Capes, e analisamos cinco trabalhos, sendo uma tese e quatro dissertações. De forma geral, os resultados apontam que a educação especial é bem amparada legalmente em nosso país, no entanto, no IFPR as práticas inclusivas se encontram em processo lento. Atualmente, dos vinte e cinco campi, apenas sete deles contam com professor de educação especial, mas nem todos têm sala de recursos multifuncional constituída, que é uma exigência preconizada pela Resolução 4/2009, ao instituir diretrizes operacionais para o atendimento educacional especializado (AEE) na educação básica.

Palavras-chave: IFPR. Educação profissional técnica e tecnológica. Educação Especial e Inclusiva.

\section{Abstract}

Special education is a teaching modality for students with disabilities, Autistic Spectrum Disorder (ASD) and with high abilities and giftedness, enrolled in different stages and levels of education. We outline the objective of analyzing institutional actions of special education at the Federal Institute of Education (IFPR) in technical and technological professional courses. It is a qualitative research, documental and bibliographical in nature. Initially, we generally present special education as a teaching modality that seeks to be carried out through legal provisions and theoretical-methodological assumptions, based on specific themes that deal with accessibility resources and services in meeting the specific needs of its audience. Next, we list some of the main IFPR documents that provide for school inclusion, with an emphasis on the rights of the public which are in special education. In order to understand what stricto sensu researches say about investigations carried out in different IFPR campuses, we searched the Capes theses and dissertations catalog, and analyzed five works, one thesis and four dissertations. In general, the results show that special education is legally well supported in our country, however, in the IFPR inclusive practices are in a slow process. Currently, of the twenty-five campuses, only seven of them have a special education teacher, but not all have constituted a multifunctional resource room, which is a requirement established by Resolution 4/2009, by instituting operational guidelines for specialized educational care (AEE) in basic education.

Keywords: IFPR. Technical and technological professional education. Special and Inclusive Education.

\section{Resumen}

La educación especial es una modalidad de enseñanza para estudiantes con discapacidad, trastorno del espectro autista (TEA) y con altas capacidades y superdotación, matriculados en diferentes etapas y niveles de educación. Planteamos el objetivo de analizar las acciones institucionales de educación especial en el Instituto 
Federal de Educación (IFPR) en cursos profesionales técnicos y tecnológicos. Se trata de una investigación de carácter cualitativo, documental y bibliográfico. Inicialmente, generalmente presentamos la educación especial como una modalidad de enseñanza que busca realizarse a través de disposiciones legales y supuestos teórico-metodológicos, con base en temas específicos que abordan los recursos y servicios de accesibilidad en la satisfacción de las necesidades específicas de su público. A continuación, enumeramos algunos de los principales documentos de la IFPR que prevén la inclusión escolar, con énfasis en los derechos del público en la educación especial. Para comprender lo que dicen las investigaciones stricto sensu sobre las investigaciones realizadas en los diferentes campus de la IFPR, se buscó en el catálogo de tesis y disertaciones de Capes, y se analizaron cinco trabajos, una tesis y cuatro disertaciones. En general, los resultados muestran que la educación especial está bien respaldada legalmente en nuestro país, sin embargo, en la IFPR las prácticas inclusivas están en un proceso lento. Actualmente, de los veinticinco campus, solo siete de ellos cuentan con docente de educación especial, pero no todos han constituido un salón de recursos multifuncional, lo cual es un requisito establecido por la Resolución 4/2009, al instituir lineamientos operativos para la atención educativa especializada (AEE) en educación básica.

Palabras clave: IFPR. Educación profesional técnica y tecnológica. Educación especial e inclusiva.

\section{Introdução}

A educação especial é uma modalidade de ensino que assegura aos estudantes que apresentam deficiência, Transtorno do Espectro Autista (TEA) e altas habilidades ou superdotação, condições adequadas de aprendizagem, conforme suas necessidades específicas. Para que essa demanda seja alcançada, o trabalho educativo precisa ser (re) organizado por meio de serviços, como o atendimento educacional especializado (AEE), e recursos para adaptações materiais e pedagógicas, flexibilizações curriculares, dentre outras.

Sobre a educação profissional técnica e tecnológica, consideramos as reflexões de Kuenzer (2010) quando aponta para a necessidade de entendimento entre trabalho, ciência e cultura na formação da consciência individual e coletiva dos estudantes. De forma análoga, Saviani (2003) atenta para a necessidade de o trabalhador conhecer integralmente o processo de produção na busca da compreensão de sua totalidade, de seu caráter, enfim, de sua essência. Nessa mesma linha de pensamento, Frigotto (2010) coaduna com tal entendimento ao pontuar que a educação na atualidade, com todos os seus conflitos, responde e é vital na manutenção das relações de poder que 
existem no plano estrutural e conjuntural da sociedade capitalista. Dada essa complexidade, entendemos com esses autores a necessidade de um ensino politécnico mediado pelo conhecimento, ciência e tecnologia, na formação do homem omnilateral, em que o trabalho ocupa uma dimensão ontológica nesse processo, considerando as relações sociais, políticas e contextuais que marcam a educação atual.

No presente texto tratamos de estudantes com deficiência e, inicialmente, empreendemos estudo sobre as principais normativas mundiais, como a Declaração Universal dos Direitos Humanos (1948); a Declaração Mundial sobre Educação para Todos (1990); a Declaração de Salamanca (1994), dentre outros dispositivos que norteiam as políticas públicas para a educação inclusiva. Apresentamos também documentos nacionais que asseguram a exequibilidade da educação especial na esfera federal de ensino.

No que se refere à educação especial no IFPR, elencamos seus principais documentos, como a Resolução 11/2009, que aprova a Política de Apoio Estudantil do Instituto Federal do Paraná (2009); a Resolução 53/2011, a qual altera os Artigos $7^{\circ}, 8^{\circ}$ e $12^{\circ}$ da Resolução n $11 / 09$, que determina a Política de Apoio Estudantil do Instituto Federal do Paraná (2011); a Resolução 54/2011, que dispõe sobre a Organização Didático Pedagógica da Educação Profissional Técnica de Nível Médio e Formação Inicial e Continuada de Trabalhadores no âmbito do Instituto Federal do Paraná - IFPR (2011); a Resolução 55/2011, que dispõe sobre a Organização Didático Pedagógica da Educação Superior no âmbito do Instituto Federal do Paraná - IFPR (2011); o Plano de Desenvolvimento Institucional (PDI) (2019-2023) (2018); o Regimento Interno comum a todos os campi do IFPR (2014); o Estatuto do IFPR (2014), o Manual de Competências (2015); além de dois editais de seleção de estudantes para ingresso no ano letivo de 2021.

Para a análise da literatura que discute a temática educação especial e IFPR, realizamos revisão de literatura no catálogo de teses e dissertações da capes, localizamos dez pesquisas, e por questões de atendimento à proposição do objetivo da pesquisa, analisamos cinco delas.

Nossa pesquisa se justifica pela necessidade de compreensão adequada da organização da educação especial no IFPR, a partir dos principais aspectos da legislação internacional e nacional e institucional em vigor que orientam as políticas 
públicas para a educação especial e inclusiva, e as suas implicações na compreensão das bases teóricas e práticas que fundamentam o AEE aos estudantes público-alvo da educação especial, sendo alunos com deficiência, TEA e altas habilidades ou superdotação. Para isso, questionamos: como a educação especial é contemplada nos dispositivos legais do IFPR e o que dizem as pesquisas sobre essa modalidade de ensino na educação profissional técnica e tecnológica? No intuito de compreender essa problemática, traçamos o objetivo de analisar ações institucionais de educação especial e inclusiva no Instituto Federal de Educação (IFPR) nos cursos profissionais técnicos e tecnológicos. Trata-se de uma pesquisa qualitativa, de natureza documental e bibliográfica.

Conforme discorremos, o presente texto se organiza em três tópicos: a educação especial como modalidade inclusiva - dispositivos legais e teóricometodológicos, para isso, organizamos dois subtópicos, no primeiro enfatizamos os aspectos legais mundiais e nacionais gerais, no qual elencamos documentos que asseguram o direito à educação inclusiva; e no segundo, tratamos, de forma geral, das principais temáticas que corroboram na organização teórico-metodológica da educação inclusiva. $\mathrm{Na}$ sequência, tratamos das especificidades do IPPR, e organizamos um tópico com os principais documentos norteadores da educação inclusiva no IFPR, com um subtópico em que apresentamos o resultado de revisão de literatura sobre o que dizem as pesquisas sobre educação especial no IFPR.

\section{A educação especial como modalidade inclusiva: dispositivos legais e teórico-metodológicos}

A educação especial é uma necessidade decorrente da heterogeneidade humana, pois aprendemos e nos desenvolvemos conforme nossa subjetividade e identidade, que são influenciadas por fatores biopsicossociais.

Conforme a legislação e literatura que dispõem sobre a educação especial, esta é uma modalidade de ensino que se realiza nas diferentes etapas e níveis de ensino e é um campo de conhecimento presente nas diversas áreas de estudos. 
No contexto escolar, as especificidades dos que não aprendem ao mesmo tempo e da mesma forma que os demais estudantes demandam reflexões e atitudes políticas e pedagógicas no (re)direcionamento do processo de ensino e aprendizagem.

A seguir, tratamos dos aspectos legais que dispõem sobre o direito de todos de se apropriar dos conteúdos socioculturais enquanto ferramentas que promovem o desenvolvimento humano.

\section{Principais documentos que asseguram o direito à educação inclusiva}

Um marco que consideramos balizador na compreensão de se incluir todos na conquista dos direitos humanos, e em destaque os educacionais, é o que traz a Declaração Universal dos Direitos Humanos, de 1948, quando, logo de início, em seu artigo $1^{\circ}$ assevera que "Todos os seres humanos nascem livres e iguais em dignidade e direitos" (ONU, 1948), que pelo ensino e educação devem ser assegurados a todos, indistintamente.

Em nosso país, o marco vigente que orienta as políticas nacionais é a atual constituição federal (BRASIL, 1988). Considerada como a carta magna, ou seja, a lei maior, conforme preceitos da Declaração Universal dos Direitos Humanos e do anseio por princípios democráticos que norteiem a vida social e política dos brasileiros, como o que traz o artigo 205, o qual assegura que "A educação, direito de todos e dever do Estado e da família, será promovida e incentivada com a colaboração da sociedade, visando ao pleno desenvolvimento da pessoa, seu preparo para o exercício da cidadania e sua qualificação para o trabalho” (BRASIL, 1988).

No que se refere à educação especial, o inciso III do art. 208 dispõe sobre a legitimidade serviço de "atendimento educacional especializado aos portadores de deficiência, preferencialmente na rede regular de ensino" (BRASIL, 1988). O inciso I do art. 206 trata da necessidade de "igualdade de condições para o acesso e permanência na escola" (BRASIL, 1988).

Após quarenta e cinco anos da aprovação da Declaração dos Direitos Humanos, especialmente os países menos desenvolvidos, estavam vivenciando um contexto de muitas desigualdades sociais, e dentre as negligências, as ligadas à 
educação escolar, como falta de acesso ao ensino básico, evasão, repetência, enfim, um generalizado insucesso nas políticas públicas para a educação, pois muitos não tinham acesso a material impresso, às classes de alfabetização e outros serviços educacionais elementares. Diante dessa realidade, em 1990, líderes mundiais se reúnem em Jomtien, na Tailândia, e um importante documento a Declaração Mundial sobre Educação para Todos, com o intuito de se estabelecer compromissos mundiais à população marginalizada uma vida mais digna por meio de conhecimentos escolares básicos de crianças, jovens e adultos, dentre outras conquistas. Em síntese, essa declaração estabelece o acesso universal à educação e o combate ao analfabetismo como prioridade mundial.

Em 1994, líderes mundiais preocupados, sobretudo, com a exclusão das pessoas com deficiência, realizam em Salamanca, na Espanha, a Conferência Mundial sobre Educação Especial, com o objetivo de fornecer diretrizes básicas para a orientação na formulação de políticas públicas e reformas em sistemas educacionais, rumo a um movimento mundial de inclusão social e escolar. Essa declaração reforça a necessidade de atender os direitos das pessoas considerando suas especificidades de aprendizagem, isto é, as escolas precisam se ressignificar para atender a todos os estudantes, especialmente em classes comuns de aprendizagem àqueles que apresentam algum tipo de deficiência. Em suma, a Declaração de Salamanca enfatiza a ideia de educação para todos, garantindo igualdades de oportunidades sociais, a necessidade de universalizar a educação de qualidade com equidade, isto é, concentrar a atenção na aprendizagem a partir de um ambiente adequado, com recursos físicos, materiais e humanos e teóricos-metodológicos que atendam às especificidades de todos os estudantes, inclusive os que apresentam deficiências.

A mobilização pelos direitos à educação, preconizada na Constituição Brasileira, é colocada e garantida na Lei de Diretrizes e Bases da Educação Nacional/LDBEN - Lei N 9.394/1996 (BRASIL, 1996). A LDBEN traz orientações gerais para a educação infantil, educação básica, ensino superior de graduação e pósgraduação, e é a partir do que está colocado nela, que cada instância (federal, estadual, municipal e distrital) organiza os seus sistemas, adaptando as suas realidades e especificidades, o que inclui a organização dos currículos com os conteúdos comuns mínimos para todos os estudantes brasileiros. 
Ainda sobre educação especial, a atual LDBEN nº 9.394, de 20 de dezembro de 1996 estabelece que os estudantes com deficiência ou TEA devem estudar preferencialmente no ensino regular, em escolas inclusivas, com igualdade de direitos e oportunidades teórico-metodológicas para todos se desenvolverem. O seu Capítulo III, art. $4^{\circ}$, inciso III, dispõe que é dever do Estado garantir AEE gratuito aos educandos com necessidades especiais, preferencialmente na rede regular de ensino (BRASIL, 1996). Os princípios de inclusão escolar também estão presentes em seu artigo 58, ao conceituar a educação especial como modalidade de educação escolar, oferecida preferencialmente na rede regular de ensino, para educandos com necessidades especiais (BRASIL, 1996). O seu artigo 59, em seu inciso I, dispõe sobre o dever dos sistemas de ensino de assegurar "currículos, métodos, técnicas, recursos educativos e organização específicos, para atender às suas necessidades” (BRASIL, 1996), aspecto que resvala na necessidade e importância da formação docente para atender as especificidades do público da educação especial. Além disso, os demais incisos (II a V) deste artigo tratam da "terminalidade específica para aqueles que não puderem atingir o nível exigido para a conclusão do ensino fundamental"; a formação docente específica para atender essa modalidade de ensino; e, o "acesso igualitário aos benefícios dos programas sociais suplementares disponíveis para o respectivo nível do ensino regular". Já o artigo 59-A (incluído pela Lei no 13.234/2015) assevera sobre a necessidade de composição de cadastro nacional de alunos da educação básica e superior com altas habilidades ou superdotação, com o intuito de se implementar políticas públicas de incentivo ao desenvolvimento desses estudantes.

A Resolução CNE/CEB n. ${ }^{\circ}$ 2/2001, institui Diretrizes Nacionais para a Educação Especial na Educação Básica, em todas as suas etapas e modalidades, para alunos que apresentam necessidades educacionais especiais. Conforme o que preconiza essa normativa, os sistemas de ensino devem matricular todos os alunos, indistintamente de terem ou não necessidades especiais, cabendo às escolas se organizarem para prover condições necessárias para uma educação de qualidade para todos, especialmente no AEE, com professores capacitados e currículos adequados às necessidades educacionais dos estudantes, possibilitando seu desenvolvimento acadêmico e social. 
A Convenção sobre os Direitos das Pessoas com Deficiência e seu Protocolo Facultativo, assinados em 30 de março de 2007, em Nova York, EUA, e internalizada no Brasil pelo Decreto Legislativo n ${ }^{\circ} 186$, de 09 de julho de 2008, e promulgada pelo Decreto n ${ }^{\circ}$ 6.949, de 25 de agosto de 2009, é outro documento que assegura direitos dos estudantes da educação especial. Isto é, representa um compromisso de garantir os direitos e liberdades fundamentais das pessoas com deficiência. Dentre os aspectos tratados na presente convenção, foi a definição de "adaptação razoável”, como aquela necessária para que as pessoas com deficiência possam usufruir de suas liberdades fundamentais, sem ônus indevido ou excessivo, e "desenho universal", como oferta de produtos, ambientes, programas e serviços sem necessidade de adaptações, bem como "discriminação por motivo de deficiência", como a realizada devido à deficiência, aspecto que influencia negativamente no exercício dos direitos dessas pessoas.

A política em vigência para a educação especial é a Política Nacional de Educação Especial na Perspectiva da Educação Inclusiva — PNEEPEI (BRASIL, 2008). Sobre o AEE, dispõe que este serviço apresenta caráter de suporte e apoio à educação regular, que se realiza no atendimento à escola, ao professor da classe regular e, sobretudo, ao aluno em suas necessidades específicas de aprendizagem, realizado em um contexto escolar acessível que promove o convívio, a estimulação das interrelações e o desenvolvimento de habilidades acadêmicas nas diferentes áreas do conhecimento. A PNEEPEI assegura a oferta do AEE nas salas de recursos multifuncionais, na rede regular de ensino, com vistas ao convívio e a aprendizagem do público da educação especial com os demais estudantes, em um mesmo contexto escolar. Para essa política, o AEE,

[...] tem como função identificar, elaborar e organizar recursos pedagógicos e de acessibilidade que eliminem as barreiras para a plena participação dos estudantes, considerando suas necessidades específicas. As atividades desenvolvidas no atendimento educacional especializado diferenciam-se daquelas realizadas na sala de aula comum, não sendo substitutivas à escolarização. Esse atendimento complementa e/ou suplementa a formação dos estudantes com vistas à autonomia e independência na escola e fora dela (BRASIL, 2008, p. 11). 
O AEE é composto por um conjunto de serviços, atividades e recursos pedagógicos planejados e organizados de forma a complementar e suplementar a formação do estudante, com o intuito de assegurar o acesso, permanência e educação de qualidade a todos em igualdade de condições, por meio de atividades pedagógicas realizadas em trabalho colaborativo entre professores da sala comum, professor AEE e equipe multidisciplinar da escola.

A Resolução n 04/2009 do CNE/CEB “Institui Diretrizes Operacionais para o Atendimento Educacional Especializado na Educação Básica”, modalidade Educação Especial, em seu art. $3^{\circ}$ dispõe que a educação especial se realiza em todos os níveis, etapas e modalidades, tendo esse atendimento como parte integrante do processo educacional.

O Decreto n. ${ }^{\circ}$ 7.611, de 17 de novembro de 2011 dispõe sobre a educação especial e o AEE. Este Decreto recebeu orientações da Nota Técnica n ${ }^{\circ} 62$ MEC/SECADI/PEE- "Orientações aos Sistemas de Ensino sobre o Decreto n ${ }^{\circ}$ 7.611/2011" em resposta ao entendimento da PNEEPEI; a oferta complementar ou suplementar do AEE e demais serviços da educação especial; o financiamento público às instituições privadas filantrópicas de Educação Especial; o Plano Nacional dos Direitos das Pessoas com Deficiência — 2011/2014 e a construção da educação inclusiva nos sistemas de ensino; a organização da educação bilíngue nas escolas da rede pública de ensino; e o Decreto nº 7.611 (BRASIL, 2011) a luz dos fundamentos legais da educação inclusiva.

A Declaração de Incheon (2015), aprovada no Fórum Mundial de Educação, ocorrido na cidade de Incheon/Coreia do Sul, de 19 a 22 de maio de 2015, com o tema "Educação 2030: rumo a uma educação de qualidade inclusiva e equitativa e a educação ao longo da vida para todos”. Essa Declaração determina referências, princípios e desafios, distribuídos em vinte itens, com objetivos, ações e metas a serem cumpridos até o ano de 2030, com o propósito de se alcançar uma educação inclusiva e equitativa, com oportunidades de aprendizagem ao longo da vida, bem como ser transformadora e universal, inspirada em uma visão humanística e do desenvolvimento, voltada para o respeito aos direitos humanos e à dignidade da pessoa, nos aspectos de justiça social, inclusão, proteção, diversidade cultural, linguística e étnica. 
Enfim, a Declaração de Incheon (2015) enfatiza a necessidade de enfrentamento de todas as formas de exclusão e marginalização, especialmente as praticadas contra as pessoas com deficiência. Destaca a necessidade de empoderamento profissional dos professores, além de se fazer uso das tecnologias de informação e comunicação na promoção de aprendizagens flexíveis, utilizadas para fortalecer os sistemas de educação de qualidade.

A Lei $n^{\circ}$ 13.146, de 06 de julho de 2015, é considerada um importante conquista para a inclusão escolar e social das pessoas com deficiência, conhecida como Lei Brasileira de Inclusão (LBI), a qual afirma em seu artigo $1^{\circ}$ que a finalidade desta Lei é “[...] destinada a assegurar e a promover, em condições de igualdade, o exercício dos direitos e das liberdades fundamentais por pessoa com deficiência, visando à sua inclusão social e cidadania".

\section{Orientações teórico-metodológicas para a educação inclusiva}

Refletir sobre educação inclusiva é colocar em pauta as possibilidades epistemológicas de aprendizagem de estudantes que apresentam algum tipo de impedimento ou dificuldade em suas vias de aferências e eferências, sejam físicas, intelectuais, sensoriais ou outras que acessam ou participam da aquisição de conhecimentos trabalhados nas diferentes componentes curriculares.

Com base nas especificidades dos estudantes público da educação especial, há algumas temáticas que carecem de organização teórico-metodológica para mediar o trabalho docente e contribuir com a aprendizagem do estudante com deficiência, além sobretudo de conhecimentos sobre cada tipo de deficiência, TEA e altas habilidades ou superdotação.

De forma geral, esses fundamentos perpassam os aspectos de acessibilidade, como os de natureza comunicacional, atitudinal, interacional, arquitetônica, pedagógica, tecnológica e outras precisam ser realizadas, como os recursos e serviços das tecnologias assistivas (TA), os materiais, técnicas e estratégias do desenho universal de aprendizagem (DUA), o uso da língua brasileira de sinais (Libras) na educação bilíngue, o uso de braille e soroban na aprendizagem e comunicação tátil, 
os recursos de tradução de imagens e escrita em palavras, por meio de audiodescrição, as adaptações e flexibilizações que permitem o acesso ao currículo e outros.

De acordo com o inciso I, do artigo $3^{\circ}$ da Lei 13.146/2015, entendemos acessibilidade como:

[...] possibilidade e condição de alcance para utilização, com segurança e autonomia, de espaços, mobiliários, equipamentos urbanos, edificações, transportes, informação e comunicação, inclusive seus sistemas e tecnologias, bem como de outros serviços e instalações abertos ao público, de uso público ou privados de uso coletivo, tanto na zona urbana como na rural, por pessoa com deficiência ou com mobilidade reduzida.

O termo acessibilidade, veiculado no Dicionário de sinônimos on-line ${ }^{1}$, conta com quatro categorias semânticas de significação: a) "Quem tem fácil acesso", com seis acepções; b) “Com fácil aproximação”, somando igualmente seis significados; c) "De fácil compreensão", totalizando cinco sinônimos; d) "De fácil realização", também com cinco significados.

De acordo com o que preconiza a citada Lei e nos diversos conceitos trazidos pelo dicionário mencionado, além do que é regulamentado pela Associação Brasileira de Normas Técnicas - ABNT NBR 9050, de 03 de agosto de 2020, que regula questões de acessibilidade em nosso país, como sendo:

[...] possibilidade e condição de alcance, percepção e entendimento para utilização, com segurança e autonomia, de espaços, mobiliários, equipamentos urbanos, edificações, transportes, informação e comunicação, inclusive seus sistemas e tecnologias, bem como outros serviços e instalações abertos ao público, de uso público ou privado de uso coletivo, tanto na zona urbana como na rural, por pessoa com deficiência ou mobilidade reduzida (NBR 9050, 2020, p. 12).

Na dinâmica AEE estendemos o entendimento da expressão acessibilidade a outros aspectos presentes na dialética do ensinar e aprender a partir de serviços e recursos específicos aos estudantes com deficiência, dentre os demais. Ou seja, há diferentes barreiras que precisam ser transpostas que vão além do espaço físico e urbanístico, as quais dificultam e muitas vezes impossibilitam a aprendizagem adequada.

\footnotetext{
1 https://www.sinonimos.com.br/ 
A LBI de 2015 apresenta ainda em seu artigo $3^{\circ}$, inciso II o conceito de desenho universal (DU), como sendo: “[...] concepção de produtos, ambientes, programas e serviços a serem usados por todas as pessoas, sem necessidade de adaptação ou de projeto específico, incluindo os recursos de tecnologia assistiva" (BRASIL, 2015). A partir dessa conceituação, nos remetemos ao entendimento de que o DU está diretamente ligado com a exequibilidade da acessibilidade, isto é, se produtos, serviços, ambientes e outros forem projetados para atender a todas as pessoas, com ou sem deficiência, estamos promovendo a inclusão de uma forma abrangente.

Há na literatura a expansão do DU para DUA (desenho universal para a aprendizagem). Conforme Eladio Sebastián-Heredero (2020), em tradução² e revisão de literatura pondera que,

O DUA considera a variabilidade/diversidade dos estudantes ao sugerir flexibilidade de objetivos, métodos, materiais e avaliações, permitindo aos educadores satisfazer carências diversas. O currículo que se cria seguindo a referência do DUA é planejado desde o princípio para atender às necessidades de todos os alunos, fazendo com que mudanças posteriores, assim como o esforço e o tempo vinculados a elas, sejam dispensáveis. A referência do DUA estimula a criação de propostas flexíveis desde o início, apresentando opções personalizáveis que permitem a todos os estudantes progredir a partir de onde eles estão, e não de onde nós imaginamos que estejam. As opções para atingi-los são variadas e suficientemente fortes para proporcionar uma educação efetiva para todos os estudantes (HEREDERO, 2020, p. 735).

Em suma, o DUA busca atingir a totalidade dos estudantes, universalizando, com isso, a apropriação do conhecimento. Com base nessas possibilidades para a aprendizagem.

Para que a educação especial se efetive, alguns aspectos de acessibilidade, que se realizam por meio do DUA, entretanto, as tecnologias assistivas (TA) são indispensáveis para sua execução. A LBI de 2015, no artigo $3^{\circ}$, inciso III conceitua tecnologia assistiva ou ajuda técnica como:

\footnotetext{
2 “As Diretrizes do Desenho Universal para a Aprendizagem - DUA (UDL na língua inglesa) começaram como um projeto do Centro Nacional de Acesso ao Currículo Geral (NCAC), um acordo de colaboração entre o Centro de Tecnologias Especiais Aplicadas (CAST) e o Escritório de Programas de Educação Especial (OSEP) do Departamento de Educação dos Estados Unidos" (HEREDERO, 2020, p. 733).
} 
[...] produtos, equipamentos, dispositivos, recursos, metodologias, estratégias, práticas e serviços que objetivem promover a funcionalidade, relacionada à atividade e à participação da pessoa com deficiência ou com mobilidade reduzida, visando à sua autonomia, independência, qualidade de vida e inclusão social (BRASIL, 2015).

São várias as categorias de TA que podem ser utilizadas no ambiente escolar compreendendo dispositivos, técnicas, serviços e outros, utilizados ou adaptados conforme as necessidades de cada estudante com deficiência, dentre elas elencamos: uso de linguagem alternativa ou aumentativa, recursos de acessibilidade para uso do computador (hardware e software), sistemas de controles para ambientes, materiais adaptados para prover coordenação motora, a estimulação de resíduos visuais, o uso de recurso viso-espaciais para atender os surdos e outros.

$\mathrm{Na}$ educação especial é fundamental que o professor do AEE em parceria com os docentes do ensino comum e setor pedagógico realizem o plano de avaliação de ingresso e de intervenção prevendo, quando necessário, adaptações e flexibilizações curriculares, bem como estratégias de acessibilidade ao componente curricular incluindo o DUA e as TA necessárias para o acesso ao conhecimento.

\section{Documentos norteadores da educação inclusiva no IFPR}

A Lei $\mathrm{n}^{\mathrm{o}}$ 11.892, de 29 de dezembro de 2008 institui a Rede Federal de Educação Profissional, Científica e Tecnológica e cria os Institutos Federais de Educação, Ciência e Tecnologia (IFs), com a finalidade de revolucionar a educação profissional científica e tecnológica. Os IFs são "[...] instituições de educação superior, básica e profissional, pluricurriculares e multicampi, especializados na oferta de educação profissional e tecnológica nas diferentes modalidades de ensino [...]" (BRASIL, 2008, art. $2^{\circ}$ ). Embora o texto da referida Lei menciona o termo modalidades de ensino, não especifica a educação especial, apesar do comprometimento com uma educação profissional como política de inclusão (BRASIL, 2010). De forma análoga, a Resolução no 11, de 21 de dezembro de 2009 aprova a Política de Apoio Estudantil do IFPR, não trouxe dentre as modalidades de atendimento, o público da educação especial, aspecto que foi acrescido somente a partir de 2011, pela Resolução no 53/2011, que inclui o inciso X no artigo 1: “acesso, 
participação e aprendizagem de estudantes com deficiência, transtornos globais do desenvolvimento e altas habilidades e superdotação” (BRASIL, 2011).

Ainda no ano de 2011 foram aprovadas duas outras Resoluções no IFPR, a n 54/2011 e 55/2011, que tratam respectivamente da Organização didático-pedagógica da Educação Profissional Técnica de Nível Médio e Formação Inicial e Continuada de trabalhadores e da Organização didático-pedagógica da Educação Superior. De acordo com a análise de Yanaga (2017, p. 73),

Em ambos os documentos a única menção feita à inclusão de alunos PAEE refere-se à organização curricular, que deve levar em consideração o reconhecimento da diversidade dos sujeitos e das pessoas com deficiência e a valorização dos temas transversais como gênero, raça, violência, sexualidade, pobreza, trabalho e inclusão pelos componentes curriculares.

Nosso objeto de discussão no presente texto é essa segunda instituição, isto é, algumas especificidades do Instituto Federal do Paraná (IFPR), que teve sua criação em um contexto mais específico que os demais, quer dizer, se deu pela transformação da Escola Técnica da Universidade Federal do Paraná.

No ano de 2012 foi promulgada a Lei no 12.711, de 29 de agosto de 2012, a qual dispõe sobre o ingresso nas universidades federais e nas instituições federais de ensino técnico médio, definindo reserva mínima de vagas para estudantes negros, pardos, indígenas, pessoas com deficiência e egressos de escolas públicas. "No contexto da educação profissional tecnológica, a política de cotas é um instrumento para acesso de parcela da população que historicamente não teve oportunidade a uma formação omnilateral” (KOSTRYCKI, 2020, p. 14). De acordo com essa autora, a política de cotas para ingresso na educação pública surge como instrumento para romper atitudes de exclusão social e prover políticas inclusivas contemplando as bases para a democratização do acesso, da permanência e do sucesso escolar em uma perspectiva científica e tecnológica.

As cotas destinadas às pessoas com deficiência para ingresso no IFPR foram previstas em edital do processo seletivo a partir do ano letivo de 2016. Para o ano letivo de 2021, o IFPR prevê $80 \%$ destinadas às cotas, conforme apresentamos na Figura 1. 
Figura 1 - Distribuição de vagas gerais e vagas reservadas a cotas de inclusão em Cursos Técnicos de Nível Médio do IFPR

\begin{tabular}{|c|c|c|c|c|c|c|c|c|c|c|c|c|}
\hline & & & & & $\begin{array}{l}\text { CURSOS } \\
\text { CATEGO }\end{array}$ & RIAS DE CO & NCORRÊNCIA & & & & & \\
\hline \multirow{5}{*}{$\begin{array}{l}\text { Número } \\
\text { de vagas } \\
\text { por } \\
\text { turma }\end{array}$} & C1 & $\mathrm{C2}$ & C3 & $\mathrm{C} 4$ & C5 & C6 & $\mathrm{C} 7$ & $\mathrm{C8}$ & C9 & C10 & C11 & AC \\
\hline & \multicolumn{11}{|c|}{ COTAS DE INCLUSÄOO } & \multirow{4}{*}{$\begin{array}{c}(20 \%) \\
\text { Ampla } \\
\text { Concorrência (AC) } \\
\text { (aproximadamente } \\
20 \%, \text { considerando } \\
\text { arredondamento } \\
\text { das vagas de cotas, } \\
\text { definido na Portaria } \\
\text { Normativa MEC } n^{\circ} \\
\text { 18/2012) }\end{array}$} \\
\hline & \multicolumn{8}{|c|}{ ENSINO FUNDAMENTAL INTEGRAL EM ESCOLA PÚBLICA $(60 \%)$} & \multicolumn{3}{|c|}{ COTAS IFPR $(20 \%)$} & \\
\hline & \multicolumn{4}{|c|}{$\begin{array}{c}(50 \%) \\
\text { Renda IGUAL OU INFERIOR } \\
\text { a } 1,5 \text { salário minimo per capita }\end{array}$} & \multicolumn{4}{|c|}{$\begin{array}{c}(50 \%) \\
\text { Renda SUPERIOR } \\
\text { a 1,5 salário minimo per capita }\end{array}$} & \multirow{2}{*}{$\begin{array}{l}\text { Pretos } \\
\text { ou } \\
\text { pardos } \\
\text { (PP) }\end{array}$} & \multirow{2}{*}{$\begin{array}{l}\text { Indigenas } \\
\text { (I) }\end{array}$} & \multirow{2}{*}{$\begin{array}{l}\text { Pessoas } \\
\text { com } \\
\text { deficiência } \\
(\mathrm{PcD})\end{array}$} & \\
\hline & $\begin{array}{c}\text { Pretos, } \\
\text { pardos ou } \\
\text { indigenas } \\
\text { com } \\
\text { deficiência } \\
\text { (PPIPcD) }\end{array}$ & $\begin{array}{l}\text { Pretos, } \\
\text { pardos } \\
\text { ou } \\
\text { indigenas } \\
\text { (PPI) }\end{array}$ & $\begin{array}{l}\text { Pessoas } \\
\text { com } \\
\text { deficiência } \\
(\mathrm{PcD})\end{array}$ & $\begin{array}{c}\text { Demais } \\
\text { candidatos }\end{array}$ & $\begin{array}{c}\text { Pretos, } \\
\text { pardos ou } \\
\text { indigenas } \\
\text { com } \\
\text { deficiência } \\
\text { (PPIPcD) }\end{array}$ & $\begin{array}{l}\text { Pretos, } \\
\text { pardos ou } \\
\text { indigenas } \\
\text { (PPI) }\end{array}$ & $\begin{array}{l}\text { Pessoas } \\
\text { com } \\
\text { deficiência } \\
(\mathrm{PcD})\end{array}$ & $\begin{array}{c}\text { Demais } \\
\text { candidatos }\end{array}$ & & & & \\
\hline 16 & 1 & 1 & 1 & 2 & 1 & 1 & 1 & 2 & 1 & 1 & 1 & 3 \\
\hline 20 & 1 & 1 & 1 & 3 & 1 & 1 & 1 & 3 & 2 & 1 & 1 & 4 \\
\hline 25 & 1 & 2 & 2 & 3 & 1 & 2 & 1 & 3 & 2 & 1 & 2 & 5 \\
\hline 30 & 1 & 2 & 2 & 4 & 1 & 2 & 2 & 4 & 3 & 1 & 2 & 6 \\
\hline 35 & 1 & 3 & 2 & 5 & 1 & 2 & 2 & 5 & 4 & 1 & 2 & 7 \\
\hline 36 & 1 & 3 & 2 & 5 & 1 & 3 & 2 & 5 & 4 & 1 & 2 & 7 \\
\hline 40 & 1 & 3 & 2 & 6 & 1 & 3 & 2 & 6 & 4 & 2 & 2 & 8 \\
\hline 80 & 2 & 5 & 4 & 13 & 2 & 5 & 4 & 13 & 8 & 4 & 4 & 16 \\
\hline
\end{tabular}

Fonte: Edital 47/2020 referente ao Processo Seletivo IFPR 2021 - Cursos Técnicos em Nível Médio.

Sobre o ingresso de estudantes nos cursos de graduação, na modalidade presencial, ofertados para o ano de 2021, considerando a política de inclusão do IFPR, as vagas de inclusão estão dispostas na Figura 2.

Figura 2 - Distribuição de vagas gerais e vagas reservadas a cotas de inclusão em Cursos de Graduação IFPR

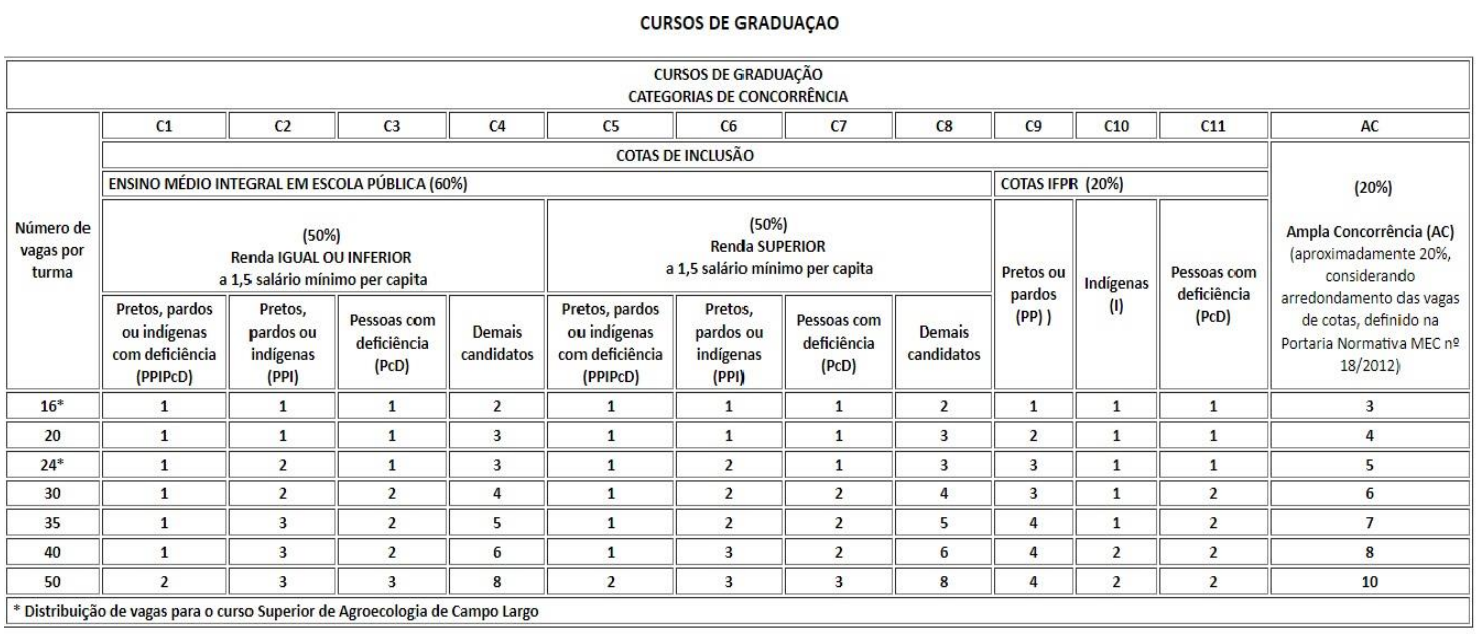

Fonte: Edital 27/2021 referente ao Processo Seletivo IFPR 2021 - Cursos de Graduação. 
Ambos os editais de processo seletivo para o ano letivo de 2021 apresentam o seguinte teor em relação à cota de vagas, dentre o público atendido, o das pessoas com deficiência.

Art. $5^{\circ} \mathrm{O}$ total das vagas ofertadas para cada curso e turma será disponibilizado da seguinte forma:

(...)

I - 50\% (cinquenta por cento) serão destinados aos candidatos que possuam renda familiar bruta mensal igual ou inferior a 1,5 (um vírgula cinco) salário mínimo nacional per capita $(R \$ 1.567,50)$, havendo reserva de vagas para candidatos de acordo com o Anexo II deste Edital: autodeclarados pretos, pardos e indígenas, com deficiência; autodeclarados pretos, pardos e indígenas; pessoas com deficiência; demais candidatos.

II - 50\% (cinquenta por cento) serão destinados aos candidatos que possuam renda familiar bruta mensal superior a 1,5 (um vírgula cinco) salário mínimo nacional per capita ( $R \$ 1.567,50)$, havendo reserva de vagas para candidatos de acordo com o Anexo II deste Edital: autodeclarados pretos, pardos e indígenas, com deficiência; autodeclarados pretos, pardos e indígenas; pessoas com deficiência; demais candidatos.

(...)

$\S 4^{\circ} 5 \%$ (cinco por cento) do total das vagas ofertadas para cada curso e turma são reservadas aos candidatos com deficiência;

Art. $6^{\circ} \mathrm{Com}$ relação às vagas que tratam o artigo $5^{\circ}$, disponibilizadas para o Processo Seletivo:

I - 80\% (oitenta por cento) destinadas às políticas de inclusão.

Como observamos, os editais (Figuras 1 e 2) contemplam 80\% das vagas para grupos de estudantes por cotas sociais e raciais, sendo $60 \%$ desse total para estudantes oriundos de escolas públicas, distribuídos em duas categorias de renda, 50\% (renda igual ou inferior a 1,5 salário mínimo per capita), cada qual organizada em quatro grupos, isto é, vagas destinadas para pretos, pardos ou indígenas com deficiência; ou pretos, pardos ou indígenas sem deficiência; ou pessoas com deficiência; ou demais candidatos. A mesma proporção se aplica para o outro 50\% (renda acima de 1,5 salário mínimo per capita). Os demais $20 \%$ das vagas se aplicam às cotas do IFPR, pretos ou pardos, indígenas e pessoas com deficiência.

Localizamos no Estatuto do IFPR (2014) menção ao público da educação especial, em seu artigo $3^{\text {a }}$, inciso IV, como princípio norteador a "inclusão de pessoas com necessidades educacionais especiais e deficiências específicas". No que tange ao atendimento das pessoas com deficiência como o previsto nos dois editais 
anteriormente apresentados, outro dispositivo oficial do IFPR como o atual Plano de Desenvolvimento Institucional (PDI) 2019-2023 é um instrumento de gestão que norteia a Instituição no que diz respeito à sua filosofia de trabalho, a missão que se propõe, seus objetivos estratégicos e as diretrizes pedagógicas que orientam suas ações. No que se refere ao atendimento de estudantes com deficiência, esse documento, por reiteradas vezes, se preocupa com questões de acessibilidade, no sentido literal de acesso físico e arquitetônico, no entanto, não percebemos preocupação maior com a execução da Meta 4 do atual Plano Nacional de Educação (PNE), que trata da educação especial nem de outras políticas públicas para essa finalidade.

Outro importante documento que ressalva o direito das pessoas com deficiência no IFPR é a Resolução no 50, de 14 de julho de 2017, a qual estabelece normas de avaliação dos processos de ensino-aprendizagem no âmbito do IFPR. O artigo 12 e se parágrafo único assim definem:

Art. 12. A avaliação do ensino-aprendizagem dos estudantes com deficiência, Transtornos Globais do Desenvolvimento, Transtornos do Espectro Autista, Altas Habilidades ou Superdotação, transtornos psiquiátricos, distúrbios e dificuldades de aprendizagem, preferencialmente, comprovadas por meio de laudos ou pareceres da respectiva área, deverá ser organizada pelos docentes juntamente aos profissionais da Seção Pedagógica e de Assuntos Estudantis, do Núcleo de Apoio às Pessoas com Necessidades Educacionais Específicas - NAPNE e registrada no Plano de Trabalho do Estudante.

Parágrafo único. O Plano de Trabalho do Estudante contempla as flexibilizações necessárias e possíveis ao processo de ensino-aprendizagem e consequentemente da avaliação, considerando a singularidade e especificidade dos estudantes, de maneira que sejam atendidos em suas necessidades e possam avançar em seu processo de aprendizagem (IFPR, 2017).

O IFPR, assim como as demais universidades públicas federais, conta com o Núcleo de Atendimento a Pessoas com Necessidades Educacionais Específicas NAPNE que tem a finalidade de promover ações inclusivas. O NAPNE é responsável em cada campus, dentre outras competências:

Dar suporte às necessidades educacionais dos alunos;

Fomentar a implantação e consolidação de políticas inclusivas no Instituto; 
Promover ações que auxiliem na permanência e êxito do estudante com necessidades educacionais específicas no IFPR, nas áreas de ensino, pesquisa e extensão (IFPR, 2015, p. 177).

Apesar dos documentos aqui apresentados, coadunamos com Goessler (2016) quando afirma que "[...] identificamos nestes documentos, mesmos nos mais atuais, a ausência de referências à legislação federal que ampara a Educação Especial e a inclusão de pessoas com NEE” (p. 104). A autora assevera sobre a contradição que constatou ao asseverar que “[...] uma instituição de ensino, pertencente à Rede Federal de Educação, não atende às prerrogativas legais de atendimento aos alunos com NEE que a própria legislação federal propõe” (ibidem). Entretanto, no ano de 2019 (Edital 08/2019), o IFPR lançou edital de concurso para professor de educação especial de nível básico, técnico e tecnológico. Atualmente, dos 25 campi apenas sete contam com docente dessa modalidade de ensino.

\section{O que dizem as pesquisas stricto sensu sobre a educação inclusiva no IFPR?}

Realizamos uma busca no catálogo de teses e dissertações da Capes sobre educação inclusiva do público da educação especial no IFPR. As palavras-chave que utilizamos foram "IFPR” AND “inclusão escolar”. Localizamos 10 (dez) pesquisas que tratam da educação profissional científica e tecnológica do IFPR, das quais excluímos 05 (cinco) por não atenderem ao propósito de nossa investigação - a educação de pessoas com deficiência. Analisamos 05 (cinco) pesquisas, sendo 04 (quatro) dissertações e 01 (uma) tese, apresentadas na tabela a seguir. 
Quadro 1 - Dissertações e teses sobre inclusão escolar na educação especial do IFPR, defendidas nos anos de 2016 a 2020

\begin{tabular}{|c|c|c|c|c|}
\hline Tipo & Ano & Título & Autor/a & $\begin{array}{c}\text { Instituição/ } \\
\text { Programa }\end{array}$ \\
\hline Tese & 2017 & $\begin{array}{l}\text { Inclusão escolar e processos } \\
\text { de resiliência em } \\
\text { adolescentes e jovens da } \\
\text { educação especial }\end{array}$ & $\begin{array}{l}\text { Thais } \\
\text { Watakabe } \\
\text { Yanaga }\end{array}$ & $\begin{array}{l}\text { Universidade Estadual } \\
\text { Paulista - UNESP - } \\
\text { Campus Presidente } \\
\text { Prudente } \\
\text { Programa de Pós- } \\
\text { graduação em Educação } \\
\text { da Faculdade } \\
\text { de Ciências e Tecnologia. }\end{array}$ \\
\hline Dissertação & 2016 & $\begin{array}{l}\text { As trajetórias escolares de } \\
\text { alunos com necessidades } \\
\text { educacionais especiais no } \\
\text { Instituto Federal do Paraná: } \\
\text { uma análise dos indicadores } \\
\text { do censo escolar }\end{array}$ & $\begin{array}{l}\text { Danieli de } \\
\text { Cássia } \\
\text { Barreto } \\
\text { Goessler }\end{array}$ & $\begin{array}{l}\text { Universidade Estadual de } \\
\text { Londrina - Pr } \\
\text { Programa de Pós- } \\
\text { graduação em Educação }\end{array}$ \\
\hline Dissertação & 2018 & $\begin{array}{l}\text { A oferta do esporte para os } \\
\text { alunos com deficiência no } \\
\text { Instituto } \\
\text { Federal do Paraná - IFPR, } \\
\text { campus Paranaguá: um } \\
\text { movimento de } \\
\text { reprodução ou resistência? }\end{array}$ & $\begin{array}{l}\text { André Santos } \\
\text { Cancella }\end{array}$ & $\begin{array}{l}\text { Universidade Federal do } \\
\text { Paraná - Curitiba } \\
\text { Programa de Pós- } \\
\text { Graduação em Educação } \\
\text { Física. }\end{array}$ \\
\hline Dissertação & 2020 & $\begin{array}{l}\text { Para além do acesso: a } \\
\text { política de cotas e o } \\
\text { abandono escolar no } \\
\text { Instituto Federal do Paraná, } \\
\text { Campus Paranaguá }\end{array}$ & $\begin{array}{l}\text { Xana } \\
\text { Machado } \\
\text { Kostrycki }\end{array}$ & $\begin{array}{l}\text { Instituto Federal do } \\
\text { Paraná - Campus Curitiba } \\
\text { Programa de Pós- } \\
\text { Graduação } \\
\text { em Educação Profissional } \\
\text { e Tecnológica }\end{array}$ \\
\hline Dissertação & 2020 & $\begin{array}{l}\text { Pressupostos para a } \\
\text { materialidade do projeto } \\
\text { pedagógico de } \\
\text { curso: um estudo a partir do } \\
\text { Curso Técnico em } \\
\text { Cooperativismo } \\
\text { Integrado ao ensino médio } \\
\text { do IFPR - Campus } \\
\text { Capanema }\end{array}$ & $\begin{array}{l}\text { Eliane de } \\
\text { Souza } \\
\text { Sabatini }\end{array}$ & $\begin{array}{l}\text { Instituto Federal Sul-Rio- } \\
\text { Grandense Campus } \\
\text { Charqueadas } \\
\text { Programa de Pós- } \\
\text { graduação } \\
\text { em Educação Profissional } \\
\text { e Tecnológica }\end{array}$ \\
\hline
\end{tabular}

Fonte: As autoras, com base em dissertações e teses pesquisadas no Banco de Teses e Dissertações da Capes (2021).

A tese intitulada "Inclusão escolar e processos de resiliência em adolescentes e jovens da educação especial", de autoria de Thais Watakabe Yanaga, foi defendida em 2017 na Unesp - Campus Presidente Prudente. A investigação buscou analisar como as ações de inclusão se articulam com processos de resiliência em adolescentes 
e jovens da educação especial, a partir da perspectiva dos alunos e professores. A pesquisa foi realizada no IFPR por meio de dois momentos, no primeiro Yanaga (2017) analisou documentos dessa instituição verificando as políticas, princípios e ações constantes sobre a inclusão de alunos da Educação Especial; no segundo, houve a pesquisa de campo, realizada em seis campi, por meio de entrevista semiestruturada com quatorze professores de diversas áreas do conhecimento e doze estudantes com deficiência — quatro surdos, dois com Síndrome de Asperger, um cego, um deficiente visual, um com Síndrome de Down, um com amputação do braço, um com raquitismo, um com mielomeningocele, e considerados em processo de resiliência. Os resultados apontaram para poucas ações de inclusão desenvolvidas no IFPR, “[...] pois a maioria das ações era realizada por iniciativa própria dos professores e da equipe pedagógica" (YANAGA, 2017, p. 8). Apesar da concepção dos docentes, os estudantes entrevistados relataram sentimento de inclusão, com exceção dos surdos. Os resultados apontaram também a necessidade de fortalecimento do Núcleo de Apoio às Pessoas com Necessidades Específicas (NAPNE) e da consolidação AEE pelo IFPR.

A primeira dissertação que analisamos trata-se da pesquisa nominada "As trajetórias escolares de alunos com necessidades educacionais especiais no Instituto Federal do Paraná: uma análise dos indicadores do censo escolar", concretizada em 2016 por Danieli de Cássia Barreto Goessler, na Universidade Estadual de Londrina, no Paraná. Para responder ao questionamento: o que as trajetórias escolares de alunos com NEE, em cursos de Educação Profissional Técnica de Nível Médio revelam sobre os resultados da articulação de políticas de educação profissional e educação especial na perspectiva inclusiva, Goessler (2016) analisou documentos institucionais do IFPR. Os resultados mostraram que o IFPR não consolidou políticas de atendimento aos estudantes com necessidades educativas especiais. "As trajetórias pós-ingresso no IFPR indicaram que, no mínimo, 51,72\% dos alunos com NEE não concluíram seus cursos. Isto representa que mais da metade do total de alunos com NEE [...] (GOESSLER, 2016, p. 8).

A segunda dissertação que compõe a presente análise é “A oferta do esporte para os alunos com deficiência no Instituto Federal do Paraná - IFPR, campus Paranaguá: um movimento de reprodução ou resistência?”, de André Santos Cancella, 
defendida em 2018, na Universidade Federal do Paraná, em Curitiba. O autor traçou o objetivo de verificar como se constitui a oferta do esporte para a pessoa com deficiência no IFPR, campus Paranaguá. Para isso, considerou a criação do sistema de cotas para a pessoa com deficiência, em 2016, nos processos de seleção do IFPR. De forma qualitativa e de cunho descritivo e analítico, Cancella (2018) realizou revisão histórica da legislação esportiva no país e dos seguintes documentos: site da Rede Federal EPCT, Plano de Desenvolvimento Institucional (PDI) do IFPR (2014-2018), Projeto Político Pedagógico (PPP) do campus Paranaguá e os Planos de Ensino Curriculares da Educação Física (PECEFs). Os resultados da pesquisa indicam que a oferta do esporte no IFPR “[...] impede a participação dos alunos com deficiência, uma vez que, enquanto políticas de ensino, atendem somente os alunos que apresentam "corpos perfeitos" ou dentro de um padrão de normalidade" (CANCELLA, 2018, p. 133). O pesquisador deixa evidente que o IFPR, à época da investigação, tratava-se de uma instituição de recente criação, e que em seu PDI não se constatou indicativos relativos a práticas esportivas.

A terceira dissertação denominada "Para além do acesso: a política de cotas e o abandono escolar no Instituto Federal do Paraná, Campus Paranaguá” produzida por Xana Machado Kostrycki em 2020, objetivou compreender quais as principais causas do abandono escolar dos estudantes atendidos pela política de cotas nos cursos de ensino médio integrado do IFPR — campus Paranaguá. A pesquisa ocorreu de forma qualiquantitativa, com coleta de dados realizadas através bibliográfica, documental e de campo. Quanto aos estudantes com deficiência, o autor constatou que as cotas destinadas a esse público foram previstas somente a partir do edital do processo seletivo do ano de 2016. Kostrycki (2020) salienta que a política de cotas, apesar de sua importância no processo de inclusão, é apenas uma das etapas desse processo, visto que parcela significativa de estudantes contemplados por cotas se evadem da escola.

A quarta e última dissertação que analisamos trata-se dos "Pressupostos para a materialidade do projeto pedagógico de curso: um estudo a partir do Curso Técnico em Cooperativismo Integrado ao ensino médio do IFPR - Campus Capanema", defendida também em 2020, por Eliane de Souza Sabatini, no Instituto Federal SulRio-Grandense Campus Charqueadas/RS. Sabatini (2020) traçou o objetivo de 
discutir a relevância do projeto pedagógico dos cursos técnicos integrados por meio de uma proposta fundamentada nos princípios teóricos do ensino médio integrado. Além de análise de documentos institucionais, a pesquisadora realizou entrevista semiestruturada com a equipe pedagógica e coordenação de curso a respeito do projeto pedagógico do Curso de Cooperativismo integrado ao Ensino Médio do IFPR - Campus Capanema, em relação aos temas de educação ambiental, educação étnicoracial, direitos humanos, inclusão e acessibilidade. Os resultados indicam, no que tange às questões de inclusão escolar, a necessidade de implementação de projetos de ensino e demais eventos referentes a temas de educação inclusiva e acessibilidade.

\section{Considerações finais}

Além dos dispositivos legais federal (leis, decretos, resoluções, deliberações, portarias, pareceres, normas técnicas e outras), que norteiam e asseguram a educação especial em uma perspectiva de educação inclusiva, o IFPR reúne outras normativas institucionais que dispõem sobre direitos de inclusão escolar de seus estudantes, dentre eles os que apresentam algum tipo de deficiência.

No presente texto apresentamos reflexões sobre alguns dos principais documentos legais do IFPR e neles situamos aspectos da educação especial, para isso, partimos das normativas federais gerais que tratam dessa temática. Para corroborar com tal entendimento, buscamos no banco de teses e dissertações da Capes trabalhos pesquisas que tratam do mesmo objeto de estudo, isto é, a educação especial como modalidade de ensino nos cursos da educação profissional técnica e tecnológica do IFPR.

Assim como os autores das pesquisas stricto sensu apresentadas neste texto, constatamos que pouco dos princípios dos documentos norteadores da educação especial estão presentes em documentos institucionais. $\mathrm{O}$ aspecto positivo que avançou foi a realização de concurso público para docentes de educação especial no ano de 2019, no entanto, a carga horária de 20 horas semanais é insuficiente para atender às demandas da educação inclusiva. Outro aspecto que precisa ser melhor implementado é sobre a formação continuada de professores em uma perspectiva de inclusão escolar. 
E, como apresentamos ao longo deste texto, aspectos legais são instrumentos que asseguram conquistas, entretanto, por si não garantem uma educação para todos, de forma democrática e inclusiva. Assim sendo, sinalizamos que outras pesquisas dessa natureza precisam ser realizadas, no sentido de refletir sobre o que está posto e o atendimento das reais necessidades dos estudantes público da educação especial, no ensino profissional técnico e tecnológico do IFPR.

\section{Referências}

ASSOCIAÇÃO BRASILEIRA DE NORMAS TÉCNICAS. NBR 9050: Acessibilidade a edificações, mobiliário, espaços e equipamentos urbanos. Rio de Janeiro: ABNT, 2020.

BRASIL. Constituição Federal do Brasil, de 05 de outubro de 1988. Disponível em: http://www.planalto.gov.br/ccivil_03/Constituicao/Constituicao.htm. Acesso em: 28 fev. 2020 .

BRASIL. Lei $\mathrm{n}^{\circ}$ 9.394, de 20 de dezembro de 1996. Disponível em: http://www.planalto.gov.br/CCIVIL_03/leis/L9394.htm. Acesso em: 28 fev. 2020.

BRASIL. CNE/CEB. Resolução n ${ }^{\circ}$ 2, de 11 de setembro de 2001. Institui Diretrizes Nacionais para a Educação Especial na Educação Básica. Disponível em: http://portal.mec.gov.br/cne/arquivos/pdf/CEB0201.pdf. Acesso em: 03 ago. 2020.

BRASIL. Política Nacional da Educação Especial na Perspectiva da Educação Inclusiva. 2008. Disponível em: http://portal.mec.gov.br/seesp/arquivos/pdf/politica.pdf. Acesso em: 13 out. 2020 .

BRASIL. CNE/CEB. Resolução $\mathrm{n}^{\circ}$ 4, de 02 de outubro de 2009. Institui Diretrizes Operacionais para o Atendimento Educacional Especializado na Educação Básica, modalidade Educação Especial. Disponível em: http://portal.mec.gov.br/dmdocuments/rceb004_09.pdf. Acesso em: 21 jul. 2020.

BRASIL. Decreto n ${ }^{\circ}$ 7.611, de 17 de novembro de 2011. Dispõe sobre a educação especial, o atendimento educacional especializado e dá outras providências. Disponível em: http://www.planalto.gov.br/ccivil_03/_ato2011-2014/2011/decreto/d7611.htm. Acesso em: 21 jul. 2020.

BRASIL. Lei no 13.146, de 06 de julho de 2015. Institui a Lei Brasileira de Inclusão da Pessoa com Deficiência (Estatuto da Pessoa com Deficiência). Disponível em: http://www.planalto.gov.br/ccivil_03/_ato2015-

2018/2015/lei/113146.htm\#: :text=O $\% 20$ direito $\% 20 \mathrm{ao} \% 20$ transporte $\% 20 \mathrm{e}, \mathrm{e} \% 20$ barreira s\%20ao\%20seu\%20acesso. Acesso em: 22 ago. 2020.

CANCELLA, A. S. A oferta do esporte para os alunos com deficiência no Instituto Federal do ParanáIFPR, campus Paranaguá: um movimento de reprodução ou resistência? 2018. 144f. Orientador: Wanderdey Marchi Junior. Dissertação (Mestrado em Educação Física) Universidade Federal do Paraná - UFPR - Curitiba/PR, 2018. 
FRIGOTTO, G. A relação da educação profissional e tecnológica com a universalização da educação básica. In: MOLL, J. et al. Educação Profissional e Tecnológica no Brasil Contemporâneo: desafios, tensões e possibilidades. Porto Alegre: Artmed: 2010. p. 159-174.

GOESSLER, D. C. B. As trajetórias escolares de alunos com necessidades educacionais especiais no Instituto Federal do Paraná: uma análise dos indicadores do censo escolar. 2016. 213f. Orientadora: Prof ${ }^{a}$. Dr $^{a}$. Silvia Márcia Ferreira Meletti. Dissertação (Mestrado em Educação) - Universidade Estadual de Londrina - UEL - Londrina/PR, 2016.

INSTITUTO FEDERAL DO PARANÁ (IFPR). Lei 11.892, de 29 de dezembro de 2008. Institui a Rede Federal de Educação Profissional, Científica e Tecnológica, cria os Institutos Federais de Educação, Ciência e Tecnologia, e dá outras providências. Disponível em: http://www.planalto.gov.br/ccivil_03/_ato2007-2010/2008/lei/111892.htm. Acesso em: 25 jul. 2021.

INSTITUTO FEDERAL DO PARANÁ (IFPR). Lei no 12.711, de 29 de agosto de 2012. Dispõe sobre o ingresso nas universidades federais e nas instituições federais de ensino técnico de nível médio e dá outras providências. Disponível em: http://www.planalto.gov.br/ccivil_03/_ato2011-2014/2012/lei/112711.htm. Acesso em: 25 jul. 2021.

INSTITUTO FEDERAL DO PARANÁ (IFPR). Resolução no 11, de 21 de dezembro de 2009. Aprova a Política de Apoio Estudantil do Instituto Federal do Paraná, através do Processo $\mathrm{n}^{\circ}$ 63.001092/2009-57, 2009. Disponível em: https://reitoria.ifpr.edu.br/resolucao-112009. Acesso em: 25 jul. 2021.

INSTITUTO FEDERAL DO PARANÁ (IFPR). Resolução n ${ }^{\circ}$ 53, de 21 de dezembro de 2011. Altera os Artigos $7^{\circ}, 8^{\circ}$ e $12^{\circ}$ da Resolução n ${ }^{\circ} 11 / 09$, que determina a Política de Apoio Estudantil do Instituto Federal do Paraná, 2011a. Disponível em: http://reitoria.ifpr.edu.br/resolucao-532011/. Acesso em: 25 jul. 2021.

INSTITUTO FEDERAL DO PARANÁ (IFPR). Resolução no 54, de 21 de dezembro de 2011. Dispõe sobre a Organização Didático Pedagógica da Educação Profissional Técnica de Nível Médio e Formação Inicial e Continuada de Trabalhadores no âmbito do Instituto Federal do Paraná - IFPR, 2011. Disponível on-line: https://assis.ifpr.edu.br/wpcontent/uploads/2012/04/Res.-54.11-Disp\%c3\%b5e-sobre-a-

Organiza\%c3\%a7\%c3\%a3o-Did\%c3\%a1tico-Pedag\%c3\%b3gica-da-

Educa \%c3\%a7\%c3\%a3o-Tecnica-de-N\%c3\%advel-M\%c3\%a9dio-no- $\%$ c3\%a2mbito-do-

Instituto-Federal-do-Paran\%c3\%a1-IFPR.pdf. Acesso em: 25 jul. 2021.

INSTITUTO FEDERAL DO PARANÁ (IFPR). Resolução no 55, de 21 de dezembro de 2011. Dispõe sobre a Organização Didático-Pedagógica da Educação Superior no âmbito do Instituto Federal do Paraná - IFPR, 2011. Disponível em: https://reitoria.ifpr.edu.br/wpcontent/uploads/2014/08/Resolu\%C3\%A7\%C3\%A3o-55.11-ODP-Superior.pdf. Acesso em: 25 jul. 2021.

INSTITUTO FEDERAL DO PARANÁ (IFPR). Plano de Desenvolvimento Institucional (PDI-2019-2023) do IFPR. 2018. Disponível em: http://info.ifpr.edu.br/informacoesinstitucionais/pdi-plano-de-desenvolvimento-institucional/. Acesso em: 25 jul. 2021.

INSTITUTO FEDERAL DO PARANÁ (IFPR). Resolução no 8, de 30 de abril de 2014. Regimento Interno Comum aos Campus do IFPR. 2014. Disponível em: 
https://reitoria.ifpr.edu.br/wp-content/uploads/2014/01/Res.-08.2014-CONSUP.pdf. Acesso em: 25 jul. 2021.

INSTITUTO FEDERAL DO PARANÁ (IFPR). Estatuto do IFPR. 2014. Disponível em: https://reitoria.ifpr.edu.br/wp-content/uploads/2010/06/Estatuto-Consolidado-em08.04.2014.pdf. Acesso em 25 jul. 2021.

INSTITUTO FEDERAL DO PARANÁ (IFPR). Manual de Competências. IFPR, 2015. Atualizado conforme organograma Portaria $n^{\circ}$ 728/2020. Disponível em: http://info.ifpr.edu.br/wp-content/uploads/728-MC-2.1.pdf. Acesso em: 25 jul. 2021.

INSTITUTO FEDERAL DO PARANÁ (IFPR). Edital no 47, de 29 de dezembro de 2020. Torna públicas as normas que regem o Processo Seletivo IFPR 2021 para ingresso nos Cursos Técnicos de Nível Médio, na modalidade presencial, ofertados para o ano de 2021, considerando a política de inclusão do IFPR para o ingresso de estudantes nos cursos. Disponível em: http://concursos.funtefpr.org.br/ifpr2021/editais.php. Acesso em: 25 jul. 2021.

INSTITUTO FEDERAL DO PARANÁ (IFPR). Edital no 27, de 28 abril de 2021. Torna públicas as normas que regem o Processo Seletivo IFPR 2021 para ingresso nos cursos de graduação, na modalidade presencial, ofertados para o ano de 2021, considerando a política de inclusão do IFPR para o ingresso de estudantes nos cursos. Disponível em: http://concursos.funtefpr.org.br/ifpr2021es/editais.php. Acesso em: 25 jul. 2021.

KOSTRYCKI, X. M. Para além do acesso: a política de cotas e o abandono escolar no Instituto Federal do Paraná, Campus Paranaguá. 2020. 103 f. Orientadora: Prof ${ }^{a}$. Dr ${ }^{a}$. Sandra Terezinha Urbanetz. Dissertação (Mestrado em Educação Profissional e Tecnológica) - Instituto Federal do Paraná - IFPR - Campus Curitiba/PR, 2020.

KUENZER, A. Z. As políticas de educação profissional: uma reflexão necessária. In: MOLL, J. et al. Educação Profissional e Tecnológica no Brasil Contemporâneo: desafios, tensões e possibilidades. Porto Alegre: Artmed: 2010. p. 159-174.

ORGANIZAÇÃO DAS NAÇÕES UNIDAS (ONU). Declaração Universal dos Direitos Humanos. $1948 . \quad$ Disponível em: https://unesdoc.unesco.org/ark:/48223/pf0000139423. Acesso em: 28 fev. 2020.

ORGANIZAÇÃO DAS NAÇÕES UNIDAS (ONU). Declaração Mundial sobre Educação para Todos. 1990.1 Disponível em: https://www.unicef.org/brazil/declaracao-mundial-sobre-educacao-para-todosconferencia-de-jomtien-1990. Acesso em: 28 fev. 2020.

ORGANIZAÇÃO DAS NAÇÕES UNIDAS (ONU). Declaração de Salamanca. 1994. Disponível em: http://portal.mec.gov.br/seesp/arquivos/pdf/salamanca.pdf. Acesso em: 28 fev. 2020.

ORGANIZAÇÃO DAS NAÇÕES UNIDAS (ONU). Convenção sobre os Direitos da Pessoa com Deficiência da ONU. 2006. Disponível em: 
http://www.planalto.gov.br/ccivil_03/_ato2007-2010/2009/decreto/d6949.htm. Acesso em: 20 fev. 2020.

ORGANIZAÇÃO DAS NAÇÕES UNIDAS PARA A EDUCAÇÃO, CIÊNCIA E CULTURA (UNESCO). Declaração de Incheon. Aprovada em 21 de maio de 2015. Incheon, Coreia do Sul, $2015 . \quad$ Disponível em: http://www.metacognicao.com.br/wpcontent/uploads/2015/11/Declara $\%$ C3\%A7\%C3\%A3o-de-Incheon1.pdf. Acesso em: 10 jan. 2021.

SABATINI, E. de S. Pressupostos para a materialidade do projeto pedagógico de curso: um estudo a partir do Curso Técnico em Cooperativismo Integrado ao ensino médio do IFPR - Campus Capanema. 2020. 87f. Orientador: Itamar Luís Hammes. Dissertação (Mestrado em Educação Profissional e Tecnológica) - Instituto Federal Sul-Rio-Grandense Campus Charqueadas/RS, 2020.

SAVIANI, D. O choque teórico da politécnia. Trabalho, Educação \& Saúde, Rio de Janeiro, n.1, p. 131-152, 2003.

SEBASITÁN-HEREDERO, E. Diretrizes para o Desenho Universal para a Aprendizagem (DUA). Rev. Bras. Ed. Esp., Bauru, v. 26, n. 4, p. 733-768, out.-dez., 2020.

YANAGA, T. W. Inclusão escolar e processos de resiliência em adolescentes e jovens da educação especial. 2017. 227 f. Orientadora: Prof. ${ }^{a}$ Dr. ${ }^{a}$ Renata Maria Coimbra.Tese (Doutorado em Educação) - Universidade Estadual Paulista (Unesp), Campus Presidente Prudente/SP, 2017.

RECEBIDO: $30 / 11 / 2019$

APROVADO: $20 / 02 / 2020$

RECEIVED: $11 / 30 / 2019$

APPROVED: 02/20/2020

RECIBIDO: 30/11/2019

APROBADO: $20 / 02 / 2020$ 